\title{
A Randomized, Controlled Multisite Study of Behavioral Interventions for Veterans with Mental IIIness and Antipsychotic Medication-Associated Obesity
}

\author{
Zachary D. Erickson, BA, CCRP', Crystal L. Kwan, MPH, RD, CDE , Hollie A. Gelberg, PhD, RD', \\ Irina Y. Arnold, MS, MD', Valery Chamberlin, $M D^{2,3}$, Jennifer A. Rosen, PharmD, BCPP ${ }^{4,5,6}$, \\ Chandresh Shah, MD², Charles T. Nguyen, MD', Gerhard Hellemann, PhD ${ }^{8}$, Dixie R. Aragaki, MD ${ }^{3,9}$, \\ Charles F. Kunkel, MD ${ }^{3,9}$, Melissa M. Lewis, PhD ${ }^{2}$, Neena Sachinvala, MD 2,3, Patrick A. Sonza, $R N^{2}$, \\ Joseph M. Pierre, $M D^{2,3}$, and Donna Ames, $M D^{2,3}$
}

\begin{abstract}
'Research Service at VA Greater Los Angeles Healthcare System, Los Angeles, CA, USA; ${ }^{2}$ Mental Health Service at VA Greater Los Angeles Healthcare System, Los Angeles, CA, USA; ${ }^{3}$ David Geffen School of Medicine at University of California-Los Angeles, Los Angeles, CA, USA; ${ }^{4}$ Department of Pharmacy at VA Northern California Healthcare System, Martinez, CA, USA; ${ }^{5}$ University of the Pacific School of Pharmacy, Stockton, CA, USA; ${ }^{6}$ University of Southern California School of Pharmacy, Los Angeles, CA, USA; ${ }^{7}$ Department of Mental Health at VA Medical Center, Long Beach, CA, USA; ${ }^{8}$ Semel Institute for Neuroscience \& Human Behavior at University of California-Los Angeles, Los Angeles, CA, USA; ${ }^{9}$ Physical Medicine and Rehabilitation Service at VA Greater Los Angeles Healthcare System, Los Angeles, CA, USA.
\end{abstract}

BACKGROUND: Weight gain and other metabolic sequelae of antipsychotic medications can lead to medication non-adherence, reduced quality of life, increased costs, and premature mortality. Of the approaches to address this, behavioral interventions are less invasive, cost less, and can result in sustained long-term benefits.

OBJECTIVE: We investigated behavioral weight management interventions for veterans with mental illness across four medical centers within the Veterans Affairs (VA) Healthcare System.

DESIGN: We conducted a 12-month, multi-site extension of our previous randomized, controlled study, comparing treatment and control groups.

PARTICIPANTS: Veterans (and some non-veteran women) diagnosed with mental illness, overweight (defined as having a BMI over 25), and required ongoing antipsychotic therapy.

INTERVENTIONS: One group received "Lifestyle Balance" (LB; modified from the Diabetes Prevention Program) consisting of classes and individual nutritional counseling with a dietitian. A second group received less intensive "Usual Care" (UC) consisting of weight monitoring and provision of self-help.

MAIN MEASURES: Participants completed anthropometric and nutrition assessments weekly for 8 weeks, then monthly. Psychiatric, behavioral, and physical assessments were conducted at baseline and months 2, 6, and 12. Metabolic and lipid laboratory tests were performed quarterly.

KEY RESULTS: Participants in both groups lost weight. LB participants had a greater decrease in average waist circumference $[\mathrm{F}(1,1244)=11.9, \mathrm{p}<0.001]$ and percent body fat $[F(1,1121)=4.3, p=0.038]$. Controlling for

For Irina Y. Arnold, the MD degree was obtained in Russia

Electronic supplementary material The online version of this article (doi:10.1007/s11606-016-3960-3) contains supplementary material, which is available to authorized users.

Published online March 7, 2017 gender yielded statistically significant changes between groups in BMI $[\mathrm{F}(1,1246)=13.9, \mathrm{p}<0.001]$. Waist circumference and percent body fat decreased for LB women $[\mathrm{F}(1,1243)=22.5, \mathrm{p}<0.001$ and $\mathrm{F}(1,1221)=4.8, \mathrm{p}=$ 0.029 , respectively]. The majority of LB participants kept food and activity journals (92\%), and average daily calorie intake decreased from 2055 to 1650 during the study $(\mathrm{p}<$ 0.001).

CONCLUSIONS: Behavioral interventions specifically designed for individuals with mental illness can be effective for weight loss and improve dietary behaviors. "Lifestyle Balance" integrates well with VA healthcare's patientcentered "Whole Health" approach.

ClinicalTrials.gov identifier NCTO1052714.

KEY WORDS: antipsychotic; weight management; obesity; behavioral intervention; mental health.

J Gen Intern Med 32(Suppl 1):S32-S9

DOI: $10.1007 / \mathrm{s} 11606-016-3960-3$

(c) Society of General Internal Medicine 2016

\section{INTRODUCTION}

Patients taking antipsychotic drugs (APDs) may experience side effects such as obesity, diabetes, dyslipidemia, and cardiovascular disease. ${ }^{1-5}$ Weight gain can lead to medication non-adherence and subsequent psychiatric relapse. ${ }^{6,7}$ The total US cost of treatment for people with psychotic disorders in 2013 was estimated at $\$ 11.5$ billion. ${ }^{8}$ Comorbid drug addiction, tobacco dependence, and obesity may all contribute to increased costs and shortened lifespans by $10-25$ years $^{9}$ and a 3.5-fold increased mortality risk. ${ }^{10}$

Approaches to address weight gain include pharmacotherapy, ${ }^{5}$ bariatric surgery, ${ }^{11,12}$ and behavioral interventions. ${ }^{13,14}$ Pharmacotherapy, while shown to have a short-term effect, is often ineffective in the long term. ${ }^{5}$ Bariatric surgery also provides short-term results for people with psychiatric 
symptoms, but results 1 year post-surgery are significantly less than in those without psychiatric illness. ${ }^{11}$ Cognitive barriers and amotivation may accompany mental illness, affecting adherence to lifestyle changes. The weight gain liabilities of some APDs can also make it more difficult to maintain weight loss. Therefore, patients taking APDs may require additional pre- and postoperative care to improve long-term weight loss. ${ }^{11,12}$

In contrast, a behavioral approach is the least medically invasive and unlikely to have side effects associated with pharmacotherapy and surgery. The United States Preventative Services Task Force (USPSTF) found behavioral interventions can result in weight loss and improved metabolic parameters in the general population. They recommend intensive, multicomponent programs utilizing groups, individual sessions, dietary modification, exercise, self-monitoring, goal setting, addressing barriers, and maintenance planning. ${ }^{15}$

Awareness of APD-associated weight gain prompted development of behavioral interventions for patients with mental illness. Intervention studies demonstrate weight loss and improved metabolic profiles compared to control groups. $5,9,13$, 14, 16-21 While durations of interventions vary, these studies highlight the importance of nutrition and exercise modification. Weight loss interventions can reduce concomitant medication use and overall cost. ${ }^{22-24}$ This study replicated and expanded our original behavioral intervention research, ${ }^{25}$ which added to the literature with a longer 12-month intervention and focus on veterans with APD-associated obesity.

We developed a behavioral weight management program for persons taking APDs based on the Diabetes Prevention Program (DPP), a diet and exercise program that has demonstrated reduced risk of diabetes. ${ }^{26}$ Our program, tested at the VA West Los Angeles Medical Center, ${ }^{25}$ also met USPSTF recommendations for higher-intensity behavioral interventions. ${ }^{15}$ Results of the randomized, controlled study's intention-to-treat analysis indicated that intervention participants were predicted to lose an average $4.6 \mathrm{~kg}$ compared to control participants predicted to gain an average $0.6 \mathrm{~kg}$ over 12 months.

Building on the single-site trial's successes, we tested this research program at the original and three additional locations. The 12-month controlled, parallel, superiority design was retained; the intervention group was hypothesized to gain more health knowledge, make more healthy lifestyle changes, and achieve better cardiovascular and mental health outcomes. Secondary hypotheses involved weight loss negatively correlating with psychiatric symptoms while positively correlating with motivation and better treatment adherence by the intervention group. This article describes the program's efficacy at these four sites.

\section{METHODS}

This study was registered with ClinicalTrials.gov (identifier NCT01052714) and approved by Institutional Review Boards at the VA Greater Los Angeles and VA Long Beach Healthcare Systems. Participants signed informed consent after receiving detailed study information, viewing a video presentation about informed consent, ${ }^{27}$ and passing a study participation comprehension assessment. Conserved participants' guardians were required to co-sign consent.

\section{Study Population and Setting}

Research activities took place in research offices near mental health clinics at four southern California VA locations. Recruitment occurred September 2010 through March 2014 using flyers and presentations. Inclusion criteria were: age 18-70 years old; diagnosis of mental illness per DSM-IV; APD treatment; BMI over 25 or weight gain over $7 \%$ on APDs; and medical and psychiatric stability, confirmed by chart reviews and primary care provider approval. Exclusion criteria were hospitalizations within 30 days, substance abuse history without sobriety over the previous 90 days, and homelessness. Follow-up with the final participant concluded by June 2015 .

\section{Study Design}

We assumed a conventional medium effect size, with desired power of $80 \%$ and two-tailed $\alpha$ set at 0.05 , and determined a sample size of $n=60$ (per treatment group). A computer pregenerated random number list randomized participants to parallel groups with a balanced allocation ratio (1:1), with clinical raters masked to randomization. Participants were stratified by APD-associated weight-gain risk (high: clozapine/olanzapine; medium: quetiapine/risperidone; low: aripiprazole/ ziprasidone; negligible: haloperidol/other), with those on multiple medications assigned based on the highest-risk medication. Participants $(n=121)$ were randomized into the more intensive "Lifestyle Balance" intervention group (LB, $\mathrm{n}=$ 62 ) or the less intensive "Usual Care" intervention group (UC, $n=59$ ).

Assessments conducted throughout the study are in Table $1^{28-37}$ Psychiatric diagnosis was confirmed by study psychiatrists or PhD-level psychologists using the Structured Clinical Interview for DSM-IV checklist. ${ }^{38}$ Physical stability was determined by physical examination, medical records, Framingham risk assessment, ${ }^{39}$ electrocardiogram, Health/ Fitness Pre-Participation Screening Questionnaire, ${ }^{40}$ and, if necessary after an investigator reviewed all of the above, an exercise tolerance test (ETT). Of 33 participants who underwent the ETT, clinicians admitted 30 to the study.

All study participants met with a research coordinator weekly for the first 8 weeks and monthly through month 12 . At every visit, vital signs, weight, waist circumference, BMI, and body fat percentage were recorded. Participants completed a Treatment Adherence Questionnaire and Lifestyle Habits Questionnaire about food, beverage, and exercise habits. If participation ended early, month 12 assessments were completed at the final visit. 
Table 1 Schedule of Assessments

\begin{tabular}{|c|c|c|c|c|c|}
\hline \multirow[t]{2}{*}{ Assessment name } & \multicolumn{5}{|c|}{ Study visit week } \\
\hline & $\mathbf{0}$ & 8 & 26 & 38 & 52 \\
\hline Physical exam & $\mathrm{X}$ & & & & $\mathrm{X}$ \\
\hline Framingham Hard Coronary Heart Disease & $\mathrm{X}$ & & & & $\mathrm{X}$ \\
\hline American Heart Association/American & $\mathrm{X}$ & & & & \\
\hline College of Sports Medicine & & & & & \\
\hline Health/Fitness Pre-Participation Screening & & & & & \\
\hline Questionnaire & & & & & \\
\hline Exercise tolerance test & $\mathrm{X}$ & & & & $\mathrm{X}$ \\
\hline Electrocardiogram & $\mathrm{X}$ & & & & \\
\hline $\begin{array}{l}\text { Structured clinical interview for DSM-IV } \\
\text { checklist }\end{array}$ & $\mathrm{X}$ & & & & \\
\hline Brief psychiatric rating scale & $\mathrm{X}$ & $\mathrm{X}$ & $\mathrm{X}$ & & $\mathrm{X}$ \\
\hline Clinical global inventory & $\mathrm{X}$ & $\mathrm{X}$ & $\mathrm{X}$ & & $\mathrm{X}$ \\
\hline Hamilton Depression Scale & $\mathrm{X}$ & $\mathrm{X}$ & $\mathrm{X}$ & & $\mathrm{X}$ \\
\hline Beck Anxiety Scale & $\mathrm{X}$ & $\mathrm{X}$ & $\mathrm{X}$ & & $\mathrm{X}$ \\
\hline $\begin{array}{l}\text { Biopsychosocial/spiritual wellness self- } \\
\text { appraisal }\end{array}$ & $\mathrm{X}$ & $\mathrm{X}$ & $\mathrm{X}$ & & $\mathrm{X}$ \\
\hline Antipsychotic side-effects checklist & $\mathrm{X}$ & $\mathrm{X}$ & $\mathrm{X}$ & & $\mathrm{X}$ \\
\hline $\begin{array}{l}\text { Motivational interview to assess stage of } \\
\text { change }\end{array}$ & $\mathrm{X}$ & $X$ & $\mathrm{X}$ & & $\mathrm{X}$ \\
\hline $\begin{array}{l}\text { University of Rhode Island Change } \\
\text { Assessment }\end{array}$ & $\mathrm{X}$ & & $\mathrm{X}$ & & $\mathrm{X}$ \\
\hline Self-Appraisal of Illness Questionnaire & $\mathrm{X}$ & $\mathrm{X}$ & $\mathrm{X}$ & & $\mathrm{X}$ \\
\hline $\begin{array}{l}\text { World Health Organization Quality of } \\
\text { Life-BREF }\end{array}$ & $\mathrm{X}$ & & & & $\mathrm{X}$ \\
\hline $\begin{array}{l}\text { Assessment of Patient Food Preparation } \\
\text { Activity }\end{array}$ & $\mathrm{X}$ & $\mathrm{X}$ & $\mathrm{X}$ & & $\mathrm{X}$ \\
\hline $\begin{array}{l}\text { Activity Lifestyle Balance Knowledge } \\
\text { Healthy Lite }\end{array}$ & $\mathrm{X}$ & $\mathrm{X}$ & $\mathrm{X}$ & & $\mathrm{X}$ \\
\hline Quiz & & & & & \\
\hline Laboratory tests & $\mathrm{X}$ & $\mathrm{X}$ & $\mathrm{X}$ & $\mathrm{X}$ & $\mathrm{X}$ \\
\hline Vitals and anthropometric measurements & $\mathrm{X}$ & $\mathrm{X}$ & $\mathrm{X}$ & $\mathrm{X}$ & $\mathrm{X}$ \\
\hline Lifestyle habits questionnaire & $\mathrm{X}$ & $\mathrm{X}$ & $\mathrm{X}$ & $X$ & $X$ \\
\hline Treatment adherence log & $\mathrm{X}$ & $\mathrm{X}$ & $\mathrm{X}$ & $X$ & $X$ \\
\hline
\end{tabular}

\section{Fidelity}

Registered dietitians (RD) were trained to administer the LB intervention by the PI; they also worked together for 6 months during the second dietitian's training period. As part of their VA dietetic training, they learned cognitive-behavioral and motivational interviewing techniques, reinforced further by the PI. To facilitate fidelity across all sites, weekly team meetings were held to ensure a standardized intervention was being provided. The PI periodically observed and assessed fidelity of the two dietitians qualitatively using a specially designed fidelity checklist to assess quality of care during class and individual coaching sessions.

\section{Behavioral Intervention: Lifestyle Balance}

Educational Materials and Group Classes. LB participants received RD-led classes and individual nutrition counseling. The LB curriculum included 16 topics (Table 2). The first 8 weeks, 60 -min classes covered two topics per session. Monthly booster classes reinforced healthy behaviors for the remaining 10 months. Class size typically ranged from $1-4$ people. Classes utilized multi-modal techniques including colored handouts, written materials, food models, poster images, and group discussions to accommodate visual, auditory, and kinesthetic learning styles. Concepts were reviewed with
Table 2 Lifestyle Balance Program Topics

1. Welcome to the Lifestyle Balance Program

2. Effects of Antipsychotic Medications on Weight, Blood Sugar, and

Cholesterol

3. Mindful Eating

4. Portion Sizes

5. Becoming Active: A Way of Life

6. Moving Those Muscles

7. Weighing the Risks

8. Tip the Calorie Balance

9. Carbs-Simply Complex

10. Fat Facts

11. Ways to Decrease Stress

12. Take Charge of What's Around You

13. Your Food Away From Home

14. Delicious Decisions

15. Variety on Your Plate

16. Ways to Stay Motivated

repetition to address potential cognitive barriers associated with mental illness. ${ }^{41}$

Individual Nutrition Counseling. Following each class, participants met RDs for 15 to $60 \mathrm{~min}$ of individualized nutrition counseling, depending on participants' needs and time availability. RDs addressed each participant's specific nutrition-related concerns and helped participants set and accomplish both short- and long-term goals.

RDs provided a comprehensive nutrition assessment at the first session, including a 24 -h food recall ${ }^{42}$ assessing participants' dietary intake. RDs also reviewed medical records and physical activity, stage of change, ${ }^{43}$ and cognitive ability. A discussion followed about specific food and activity goals to initiate behavior change. RDs used cognitive behavioral therapy techniques, ${ }^{44}$ motivational interviewing ${ }^{45,46}$ and accountability tools, including food and activity journals. RDs reviewed these journals during participants' appointments. For data analysis, 24 -h food recalls ${ }^{42}$ were used with journals to quantify food and beverage intake changes. These data were input into the USDA "Supertracker" database ${ }^{47}$ and analyzed to assess behavioral changes.

During groups and individual sessions, RDs encouraged change using positive affirmations and praise. ${ }^{41}$ To enhance motivation and adherence to the program, participants received rewards for meeting goals such as gift certificates, tote bags, and "Healthy Plates." Following the DPP's protocol "Toolbox" and the in-vivo approach to social skills training, ${ }^{48}$ RDs met with caregivers at 12 participants' residences to discuss dietary changes; they also taught healthy cooking classes and promoted walking groups. During semi-annual class field trips, RDs provided on-site education at restaurants and grocery stores. ${ }^{41}$ Once-daily meal replacement shakes were offered when basic food and exercise changes were less effective in meeting weight loss goals; only 13 participants chose this option. ${ }^{49}$

\section{Usual Care}

UC participants met with research coordinators with a frequency and duration equivalent to individual LB counseling 
Table 4 Average Weight per Condition over Time and Stratified by BMI* Levels

\begin{tabular}{|c|c|c|c|c|}
\hline & & Week 0(kg) & Week 52 (kg) & $\begin{array}{l}\text { Change } \\
\text { (kg) }\end{array}$ \\
\hline $\mathrm{BMI}^{*}: 0-24.9$ & $\mathrm{LB}^{\dagger}$ & 70.5 & 67.5 & -2.0 \\
\hline $\mathrm{N}=2$ & $\mathrm{UC}^{\ddagger}$ & $\begin{array}{l}74.8 \\
\text { Week } 0(\mathrm{~kg})\end{array}$ & $\begin{array}{l}74.9 \\
\text { Week } 52(\mathrm{~kg})\end{array}$ & $\begin{array}{l}+0.1 \\
\text { Change }(\mathrm{kg})\end{array}$ \\
\hline $\begin{array}{l}\text { BMI: } 25- \\
29.9\end{array}$ & LB & 87.9 & 88.3 & +0.4 \\
\hline $\mathrm{N}=22$ & $\mathrm{UC}$ & $\begin{array}{l}80.7 \\
\text { Week } 0(\mathrm{~kg})\end{array}$ & $\begin{array}{l}80.1 \\
\text { Week } 52(\mathrm{~kg})\end{array}$ & $\begin{array}{l}-0.6 \\
\text { Change }(\mathrm{kg})\end{array}$ \\
\hline $\begin{array}{l}\text { BMI: } 30- \\
39.9\end{array}$ & LB & 101.0 & 99.7 & -1.3 \\
\hline$N=63$ & $\mathrm{UC}$ & $\begin{array}{l}103.1 \\
\text { Week } 0(\mathrm{~kg})\end{array}$ & $\begin{array}{l}100.3 \\
\text { Week } 52(\mathrm{~kg})\end{array}$ & $\begin{array}{l}-2.8 \\
\text { Change }(\mathrm{kg})\end{array}$ \\
\hline BMI: $40+$ & LB & 137.9 & 131.4 & -6.5 \\
\hline $\mathrm{N}=17$ & $\mathrm{UC}$ & 132.2 & 137.8 & +5.6 \\
\hline
\end{tabular}

better to LB. Those with BMIs between 25 to 40 responded better to UC. Using gender as a moderator, a significant threeway interaction was found among treatment effect, gender, and weight. The treatment effect was larger for LB women, who by 26 weeks lost on average $2.18 \mathrm{~kg}[\mathrm{~F}(1,1265)=19.6, \mathrm{p}$ $<0.001$ ] compared to between $0.5-1 \mathrm{~kg}$ for UC women and men in both groups. BMI followed: LB women decreased 0.9 points $[\mathrm{F}(1,1246)=13.9, \mathrm{p}<0.001]$. Waist circumference and body fat percentage also decreased, $2.92 \mathrm{~cm}[\mathrm{~F}(1,1243)=$ $22.5, \mathrm{p}<0.001]$ and $0.9 \%[\mathrm{~F}(1,1221)=4.76, \mathrm{p}=0.029]$, respectively.

No significant differences were found between groups for hemoglobin A1c. Lipid profiles were either non-significant (HDL-cholesterol, triglycerides) or significant in the reverse direction than hypothesized (cholesterol, LDL-cholesterol).

\section{Correlation with Psychiatric Symptoms}

While weight loss was correlated with improvement in quality of life, no significant differences in quality of life scores were seen between groups. For psychiatric symptoms measured by validated scales for depression, psychosis, and anxiety, ${ }^{28-31}$ all clinical scores decreased over time ( $\mathrm{ps}<0.001)$, but there were no differences between groups. There was evidence of an interaction effect of Beck Anxiety Inventory scores with the treatment on change in weight over time: $[\mathrm{F}(1,165)=3.7, \mathrm{p}=$ 0.05]. Analysts performed a simple slope analysis to explore this three-way interaction (Table 5). Higher anxiety scores were associated with increased treatment effect; LB participants with higher scores had more weight loss while UC participants with higher scores showed reduced weight loss or even weight gain.

Insight into psychiatric illness on the Self-Appraisal of Illness Questionnaire (SAIQ) ${ }^{36}$ showed a significant association with treatment effect on weight change $[\mathrm{F}(1,192)=6.1$, $\mathrm{p}=0.01]$ with higher scores associated with larger weight loss for LB, while for UC higher scores were associated with less weight loss or even weight gain (see Table 5). When
Table 5 Simple Slope Analyses of Predicted Weight Change from Weeks 0 to 52 with Continuous Moderators (Based on Estimated Marginal Means)

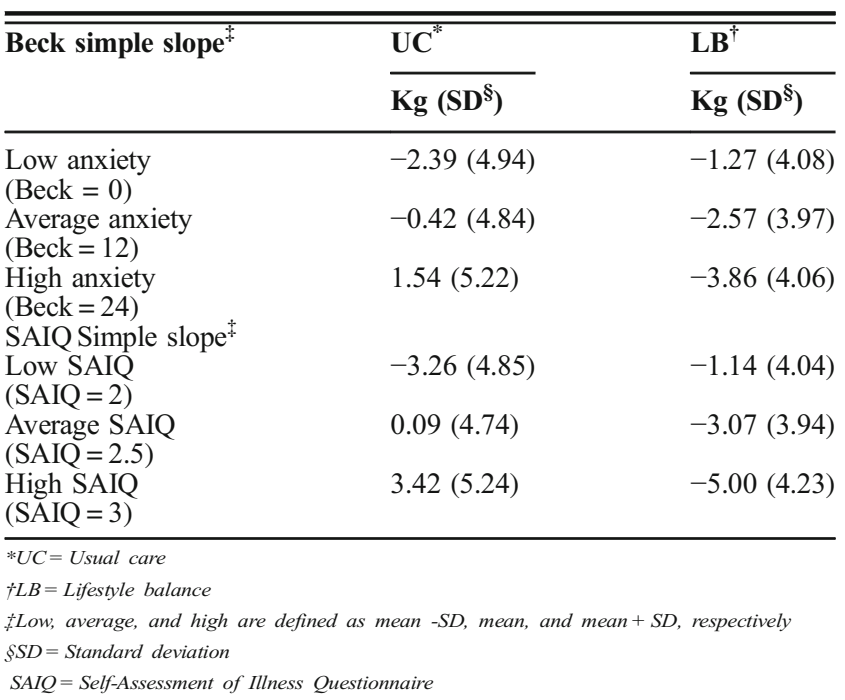

controlling for SAIQ, LB showed significantly greater weight loss than $\mathrm{UC}[\mathrm{F}(1,192=5.2, \mathrm{p}=0.02]$. When asked questions about insight regarding weight-related illness, responses also showed higher weight-related SAIQ insight scores associated with larger efficacy of LB $[\mathrm{F}(1,192)=6.6, \mathrm{p}=0.01]$ and significantly larger weight loss in LB compared to UC when controlling for SAIQ $[\mathrm{F}(1,198)=5.9, \mathrm{p}=0.02]$.

\section{Treatment Adherence}

Based on participants' self-report, no significant difference was found in medication adherence or attendance at psychiatric or study appointments between groups (97-99\%; Online Appendix 2). Ninety-two percent of LB participants completed food and activity journals on a regular basis $(n=55)$.

\section{DISCUSSION}

Participants in both LB and UC lost weight. UC was designed to be minimal, but regular research meetings to discuss diet and exercise may have been enough to motivate healthy lifestyle improvement, translating to weight loss. Even provided only self-help materials, participants may have been responsive to the accountability of frequent study appointments.

LB participants demonstrated important changes in nutritional behaviors; they reduced overall caloric intake and improved caloric quality by decreasing empty calories. They experienced additional benefits, decreasing waist circumference and adiposity, reflecting changes in body composition from exercise and weight loss. Food and activity journals also assisted participants in staying accountable to their goals.

Women seemed to be most responsive to LB, consistent with other findings. ${ }^{50}$ Although the groups' weight loss was modest, the FDA considers $5 \%$ loss clinically important, ${ }^{15}$ and 
national guidelines recommend counseling obese adults to achieve clinical benefits from a modest 3\%-5\% loss. ${ }^{51}$ Among participants completing at least 6 months, $28 \%$ lost $5 \%$ bodyweight in LB $(\mathrm{N}=42)$, while $17 \%$ lost $5 \%$ in UC $(\mathrm{N}=43)$ at last observation. The differences were not statistically significant using chi-square analyses.

Participants with BMIs under 25 or over 40 benefitted most from LB, suggesting the more intensive treatment could be targeted to these groups. Participants under 25 BMI likely passed screening because of recent rapid weight gain. Such patients may benefit from LB as a preventative approach to decrease their obesity risk. LB may also be a low-risk approach for those with BMIs over 40, who have a high chronic disease risk. For the majority of individuals taking APDs with BMIs between 25-40, one can consider UC's less intensive approach for weight loss.

LB participants with more insight into both their psychiatric illness and weight problem experienced the greatest weight loss. This implies LB was more effective for this subgroup of patients, because even with adequate insight UC participants did not lose as much weight, perhaps lacking motivational LB counseling. The association between higher anxiety scores and greater weight loss was unexpected, yet interesting, and merits future investigation.

LB participants were encouraged to reduce sugary beverage intake and portion sizes. These strategies were also found most helpful in the ACHIEVE study, ${ }^{52}$ reinforcing the idea that simple strategies are effective for those with mental illness. According to the authors, ACHIEVE participants were provided two reduced-calorie meals as part of their outpatient psychiatric rehabilitation programs, ${ }^{13}$ similar to participants in the RENEW program ${ }^{14,19}$ who received two meal replacements per day. In contrast, the primary nutrition intervention in this study involved classes and counseling to help participants independently make healthier decisions. Based on the DPP "Toolbox," one meal replacement per day was used for 13 interested individuals who struggled losing weight. ${ }^{49}$

\section{Limitations}

Study limitations included the selection of only patients with sufficient motivation to seek enrollment and competency to give informed consent because of research and HIPAA regulations. Inclusion criteria favored more stable patients, which may have yielded the extremely high treatment adherence we observed. Their health was also monitored more closely during participation, with direct access to RDs. However, some case managers within high-intensity mental health programs make scheduled home visits and may go to grocery stores with veterans, so such attention can be provided without RDs. Similarly, high levels of adherence to food and activity journaling within LB may be a result of constant reinforcement by RDs. In a real-world setting, clinician visits may be shorter because of higher patient volume. However, our results suggest simply asking patients to keep food journals may be enough to increase awareness of healthy choices. This part of LB may generalize to non-research settings as journals themselves may be effective tools for behavioral change. Simple changes can be made by reviewing journals and setting goals at each visit. Results may be less generalizable to the overall population because veterans were the primary participants, though we accepted some non-veteran women to increase their representation beyond current VA levels. Excluding UC participants who switched to LB and a drop-out rate similar to other weight management studies ${ }^{53-55}$ limited statistical power.

\section{CONCLUSION}

Like our initial LB study, this multi-site replication and extension indicate that individuals with mental illness taking APDs are capable of making lifestyle changes and improving health. Changes in nutritional behaviors, waist circumference, and adiposity point toward longterm outcomes that may lead to reduction in risk from cardiovascular and metabolic diseases. In light of moving toward personalized healthcare, hospital administrators and clinicians can adopt LB and UC into existing outpatient mental health programs, targeted to offer relatively low-cost and noninvasive means to assist veterans taking APDs. Participants with more insight into their illness benefitted most from LB. Positive outcomes for UC participants suggest less intensive treatments can also help, with monitoring and accountability the likely key elements of success. We believe these interventions can be easily adopted in mental health programs, and we hope to disseminate the program further.

Acknowledgments: The authors wish to thank Drs. Binyamin Amrami, Hyung Kim, Frederick Martin, Christopher Reist, and Heidi Weinreich as well as Matthew Baker, Luzviminda Cristobal, RN, Michael King, Jr., Eugene Beau LaPorte, Jr., Shirley Mena, RN, Hilary Meyer, Deborah Peters, RN, and Jillian Tessier for providing clinical oversight, collaboration, and research assistance. We are also thankful to the staff and Veterans of the Mental Health Clinics, MHICM programs, and PRRCs at the VA Greater Los Angeles and Long Beach Healthcare Systems for their support of this program.

This work was supported by VA Merit Review Project D7358-R from the United States (US) Department of Veterans Affairs Rehabilitation Research and Development Service, which had no input as to study design, execution, analysis, or reporting. The contents do not represent the views of the US Department of Veterans Affairs or the United States Government.

Posters presented preliminary results of this study at the Annual Meeting for the California Dietetic Association in Ontario, CA, in 2012 and at the California Academy of Nutrition and Dietetics Annual Conference in Riverside, CA, in 2016.

Corresponding Author: Donna Ames, MD; Mental Health Service at VA Greater Los Angeles Healthcare System, 11301 Wilshire Blvd. B151H, Los Angeles, CA 90073, USA (e-mail: donna.ames@va.gov).

\section{Compliance with Ethical Standards:}

Conflict of Interest: Dr. Charles Nguyen owns stock in Orexigen Therapeutics, Inc., has received research grants from Forest Laboratory, Inc., and is a consultant and part of the Speakers Bureaus for Eisai Co., Ltd., and Otsuka America Pharmaceutical, Inc. All other authors declare no conflicts of interest. 


\section{REFERENCES}

1. Wirshing DA, Boyd JA, Meng LR, Ballon JS, Marder SR, Wirshing WC. The effects of novel antipsychotics on glucose and lipid levels. J Clin Psychiatry. 2002;63(10):856-865.

2. Wirshing DA, Pierre JM, Eyeler J, Weinbach $J$, Wirshing WC. Risperidone-associated new-onset diabetes. Biol Psychiatry. 2001;50(2):148-149.

3. Wirshing DA, Spellberg BJ, Erhart SM, Marder SR, Wirshing wC. Novel antipsychotics and new onset diabetes. Biol Psychiatry. 1998;44(8):778-783.

4. Wirshing DA, Wirshing WC, Kysar L, et al. Novel antipsychotics: comparison of weight gain liabilities. J Clin Psychiatry. 1999;60(6):358-363.

5. Das C, Mendez G, Jagasia S, Labbate LA. Second-generation antipsychotic use in schizophrenia and associated weight gain: a critical review and meta-analysis of behavioral and pharmacologic treatments. Ann Clin Psychiatry. 2012;24(3):225-239.

6. Weiden PJ, Mackell JA, McDonnell DD. Obesity as a risk factor for antipsychotic noncompliance. Schizophr Res. 2004;66(1):51-57.

7. Wong MMC, Chen EYH, Lui SSY, Tso S. Medication adherence and subjective weight perception in patients with first-episode psychotic disorder. Clin Schizophr Relat Psychoses. 2011;5(3):135-141.

8. US Department of Health and Human Services: Agency for Healthcare Research and Quality. National Statistics on Mental Health Hospitalizations: Schizophrenia and other psychotic disorders. Healthcare Cost and Utilization Project (H-CUPnet). http://hcupnet.ahrq.gov/HCUPnet.jsp. Accessed June 29, 2016.

9. Ames D, Carr-Lopez SM, Gutierrez MA, et al. Detecting and managing adverse effects of antipsychotic medications. Psychiatr Clin North Am. 2016;39(2):275-311.

10. Olfson M, Gerhard T, Huang C, Crystal S, Stroup TS. Premature mortality among adults with schizophrenia in the United States. JAMA Psychiatry. 2015;72(12):1172.

11. Rutledge T, Groesz LM, Savu M. Psychiatric factors and weight loss patterns following gastric bypass surgery in a veteran population. Obes Surg. 2011;21(1):29-35.

12. Semanscin-Doerr DA, Windover A, Ashton $\mathbf{K}$, Heinberg LJ. Mood disorders in laparoscopic sleeve gastrectomy patients: does it affect early weight loss? Surg Obes Relat Dis. 2010;6(2):191-196.

13. Daumit GL, Dickerson FB, Wang N-Y, et al. A behavioral weight-loss intervention in persons with serious mental illness. N Engl J Med. 2013;368(17): 1594-1602

14. Brown C, Goetz J, Hamera E. Weight loss intervention for people with serious mental illness: a randomized controlled trial of the RENEW program. Psychiatr Serv. 2011;62(7):800-802.

15. Moyer VA. US Preventive Services Task Force. Screening for and management of obesity in adults: US Preventive Services Task Force recommendation statement. Ann Intern Med. 2012;157(5):373-378.

16. Brar JS, Ganguli R, Pandina G, Turkoz I, Berry S, Mahmoud R. Effects of behavioral therapy on weight loss in overweight and obese patients with schizophrenia or schizoaffective disorder. J Clin Psychiatry. 2005;66(2):205-212

17. McKibbin CL, Golshan S, Griver K, Kitchen K, Wykes TL. A healthy lifestyle intervention for middle-aged and older schizophrenia patients with diabetes mellitus: a 6-month follow-up analysis. Schizophr Res. 2010;121(1-3):203-206

18. Wu M-K, Wang C-K, Bai Y-M, Huang C-Y, Lee S-D. Outcomes of obese, clozapine-treated inpatients with schizophrenia placed on a six-month diet and physical activity program. Psychiatr Serv. 2007;58(4):544-550.

19. Brown C, Goetz J, Hamera E, Gajewski B. Treatment response to the RENEW weight loss intervention in schizophrenia: impact of intervention setting. Schizophr Res. 2014;159(2-3):421-425.

20. Gill KJ, Zechner M, Zambo Anderson E, Swarbrick M, Murphy A. Wellness for life: A pilot of an interprofessional intervention to address metabolic syndrome in adults with serious mental illnesses. Psychiatr Rehabil J. 2016;39(2):147-153.

21. McGinty EE, Baller J, Azrin ST, et al. Interventions to address medical conditions and health-risk behaviors among persons with serious mental illness: a comprehensive review. Schizophr Bull. 2016;42(1):96-124.

22. Kumar AA. Palamaner Subash Shantha G, Kahan S, Samson RJ, Boddu $\mathrm{ND}$, Cheskin LJ. Intentional weight loss and dose reductions of antidiabetic medications-a retrospective cohort study. PLoS One. 2012;7(2):e32395

23. Shantha GPS, Kumar AA, Kahan S, Cheah SY, Cheskin LJ. Intentional weight loss and dose reductions of antihypertensive medications: a retrospective cohort study. Cardiorenal Med. 2013;3(1):17-25.
24. Redmon JB, Bertoni AG, Connelly S, et al. Effect of the look AHEAD study intervention on medication use and related cost to treat cardiovascular disease risk factors in individuals with type 2 diabetes. Diabetes Care. 2010;33(6): 1153-1158.

25. Erickson ZD, Mena SJ, Pierre JM, et al. Behavioral interventions for antipsychotic medication-associated obesity: a randomized, controlled clinical trial. J Clin Psychiatry. 2016;77(2):e183-189.

26. Diabetes Prevention Program (DPP) Research Group. The Diabetes Prevention Program (DPP): description of lifestyle intervention. Diabetes Care. 2002;25(12):2165-2171.

27. Wirshing DA, Sergi MJ, Mintz J. A videotape intervention to enhance the informed consent process for medical and psychiatric treatment research. Am J Psychiatry. 2005;162(1):186-188.

28. Overall JE, Gorham DR. The brief psychiatric rating scale (BPRS): Recent developments in ascertainment and scaling. Psychopharmacol Bull. 1988;24(1):97-99

29. Guy W. ECDEU Assessment Manual for Psychopharmacology, Revised. Rockville, MD: US Dept. of Health, Education, and Welfare, Public Health Service, Alcohol, Drug Abuse, and Mental Health Administration, National Institute of Mental Health, Psychopharmacology Research Branch, Division of Extramural Research Programs. 1976.

30. Hamilton M. Development of a rating scale for primary depressive illness. Br J Soc Clin Psychol. 1967;6(4):278-296.

31. Beck A, Steer R. Beck Anxiety Inventory Manual. San Antonio, TX: Psychological Corp.; 1993.

32. Weiden PJ, Miller AL. Which side effects really matter? Screening for common and distressing side effects of antipsychotic medications. J Psychiatr Pract. 2001;7(1):41-47.

33. McConnaughy E, Prochaska J, Velicer W. Stages of change in psychotherapy: measurements and sample profiles. Psychotherapy. 1983;20:368-375.

34. McConnaughy E, DiClemente C, Prochaska J, Velicer W. Stages of change in psychotherapy: a follow-up report. Psychotherapy. 1989;26:494-503.

35. DiClemente CC, Hughes So. Stages of change profiles in outpatient alcoholism treatment. J Subst Abuse. 1990;2(2):217-235.

36. Marks KA, Fastenau PS, Lysaker PH, Bond GR. Self-Appraisal of Illness Questionnaire (SAIQ): relationship to researcher-rated insight and neuropsychological function in schizophrenia. Schizophr Res. 2000;45(3):203-211.

37. WHOgOL Group. The World Health Organization Quality of Life assessment (WHOQOL): position paper from the World Health Organization. Soc Sci Med. 1995;41(10):1403-1409.

38. First M, Spitzer R, Gibbon M, Williams J. Structured Clinical Interview for DSM-IV Axis I Disorders (SCID I). New York, NY: Biometric Research Department; 1997.

39. Expert Panel on Detection, Evaluation, and Treatment of High Blood Cholesterol in Adults. Executive Summary of The Third Report of The National Cholesterol Education Program (NCEP) Expert Panel on Detection, Evaluation, And Treatment of High Blood Cholesterol In Adults (Adult Treatment Panel III). JAMA. 2001;285(19):2486-2497.

40. Balady GJ, Chaitman B, Driscoll D, et al. American College of Sports Medicine Position Stand and American Heart Association. Recommendations for cardiovascular screening, staffing, and emergency policies at health/fitness facilities. Med Sci Sports Exerc. 1998;30(6):1009-1018.

41. Kwan CL, Gelberg HA, Rosen JA, et al. Nutritional counseling for adults with severe mental illness: key lessons learned. J Acad Nutr Diet. 2014; 114(3):369-374.

42. Moshfegh AJ, Rhodes DG, Baer DJ, et al. The US Department of Agriculture Automated Multiple-Pass Method reduces bias in the collection of energy intakes. Am J Clin Nutr. 2008;88(2):324-332.

43. Prochaska JO, Velicer WF. The transtheoretical model of health behavior change. Am J Health Promot AJHP. 1997;12(1):38-48.

44. Wenzel A, Brown GK, Karlin BE. Cognitive Behavioral Therapy for Depression in Veterans and Military Servicemembers: Therapist Manual. Washington, DC: US Department of Veterans Affairs; 2011.

45. Rüsch N, Corrigan PW. Motivational interviewing to improve insight and treatment adherence in schizophrenia. Psychiatr Rehabil J. 2002;26(1):23-32.

46. Miller WR, Rollnick S. Motivational Interviewing: Helping People Change. New York, NY: Guilford Press; 2012.

47. US Department of Agriculture. USDA Supertracker "Food-A-Pedia". USDA Supertracker. https://www.supertracker.usda.gov/foodapedia. aspx. Accessed October 26, 2016. 
48. Liberman RP, Glynn S, Blair KE, et al. In vivo amplified skills training: promoting generalization of independent living skills for clients with schizophrenia. Psychiatry. 2002;65(2):137-55.

49. Gelberg HA, Kwan CL, Mena SJ, et al. Meal replacements as a weight loss tool in a population with severe mental illness. Eat Behav. 2015; 19:61-64.

50. Goodrich DE, Klingaman EA, Verchinina L, et al. Sex differences in weight loss among veterans with serious mental illness: observational study of a national weight management program. Womens Health Issues. 2016.

51. Jensen MD, Ryan DH, Apovian CM, et al. 2013 AHA/ACC/TOS guideline for the management of overweight and obesity in adults: a report of the American College of Cardiology/American Heart Association Task Force on Practice Guidelines and The Obesity Society. Circulation. 2014;129(25 Suppl 2):S102-138.
52. Vazin R, McGinty EE, Dickerson F, et al. Perceptions of strategies for successful weight loss in persons with serious mental illness participating in a behavioral weight loss intervention: a qualitative study. Psychiatr Rehabil J. 2016;39(2):137-46.

53. Colombo O, Ferretti vV, Ferraris C, et al. Is drop-out from obesity treatment a predictable and preventable event? Nutr J. 2014;13:13.

54. Honas JJ, Early JL, Frederickson DD, O'Brien MS. Predictors of attrition in a large clinic-based weight-loss program. Obes Res. 2003;11(7):888-894.

55. Spring B, Sohn M-W, Locatelli SM, Hadi S, Kahwati L, Weaver FM. Individual, facility, and program factors affecting retention in a national weight management program. BMC Public Health. 2014;14:363. 